\title{
EDUCAÇÃO AMBIENTAL NA ENGENHARIA CIVIL: A PRÁTICA DO ENGENHEIRAR COM DESENVOLVIMENTO SUSTENTÁVEL
}

\author{
Jorge Luiz Oleinik Nunes ${ }^{1}$ \\ André Tremper Minasi² \\ Luis Fernando Minasi ${ }^{3}$
}

Resumo: O trabalho aqui apresentado, parte de uma tese doutoral em Educação Ambiental pela Universidade Federal do Rio Grande - FURG, analisa, no currículo da Formação do Engenheiro Civil, o desenvolvimento sustentável com as práticas do engenheirar que não podem estar divorciadas do conceito de "ecodesenvolvimento", por tudo que isto significa na construção civil. O texto traz para se pensar a formação do Engenheiro Civil com base em três princípios básicos enquanto dimensões do desenvolvimento sustentável como ecodesenvolvimento, transpondo-os da teoria acadêmica para a prática do Engenheiro Civil que busca sustentabilidade ambiental.

Palavras-chave: Educação Ambiental; Engenharia Civil; Desenvolvimento Sustentável; Ecodesenvolvimento; Formação do Engenheiro.

\begin{abstract}
The essay presented here, part of a doctoral thesis in Environmental Education by the Federal University of Rio Grande - FURG, analyzes in the curriculum of the Civil Engineer Formation the sustainable development with the engineering practices, that cannot be divorced from the concept of "ecodevelopment" for all that this means in civil construction. The text brings to mind the formation of the Civil Engineer based on three basic principles as the dimensions of sustainable development as eco-development, transposing them from academic theory to the practice of the Civil Engineer who seeks the environmental sustainability.
\end{abstract}

Keywords: Environmental Education; Civil Engineering; Sustainable Development; Ecodevelopment; Engineer Formation.

\footnotetext{
1Universidade Federal do Rio Grande - FURG. E-mail: jorgeoleinik@gmail.com Link para o Lattes: http://lattes.cnpq.br/1344965884182380

2Universidade Federal de Pelotas - UFPEL. E-mail: andreminasi@hotmail.com Link para o Lattes: http://lattes.cnpq.br/7982350340274178

3Universidade Federal do Rio Grande - FURG. E-mail: Ifminasi@terra.com.br, Link para o Lattes: http://lattes.cnpq.br/3053413467351500
} 


\section{Considerações iniciais}

A fidelidade dos princípios morais e a ética da profissão permitem ao engenheiro participar de projetos que contribuem para a construção de um mundo mais igualitário e pacífico, em que todos tenham a oportunidade de participar em termos de resultados tecnológicos que não agridam a natureza e facilitem a vida. (MARTINI, 1993, p. 21).

Trazemos neste ensaio um estudo sobre a possibilidade e a necessidade dos Cursos de Engenharia Civil, no geral e no específico de uma formação em uma Universidade Pública Federal brasileira, serem emancipadores dos sentidos humanos no que tange ao ato de engenheirar ${ }^{4}$. Este estudo, aqui apresentado, é parte da Tese Doutoral desenvolvida no Programa de Pós-Graduação em Educação Ambiental desta mesma Universidade, que estuda essa possibilidade.

Como um estudo de caso, enquanto qualidade dialética da pesquisa, levou-nos a considerar a contradição existente entre Teoria e Prática na formação do Engenheiro Civil pela Escola de Engenharia da Universidade Federal do Rio Grande - FURG, que tem sua proposta pedagógica voltada para a formação de engenheiros que possam, a partir de suas práticas, apresentar posicionamentos técnicos recheados de princípios e valores humanos.

Embora o Curso de Engenharia demonstre-se como árido pela aparência de sua matéria-prima, o trabalho que se propõe a desenvolver, pelo exposto no Projeto Pedagógico do Curso, traz em sua essência a vocação humanista do "alojar", do aconchegar em um lar os seres humanos ampliados por todas as demais possibilidades que a ciência e a tecnologia sugerem e possam preconizar.

Neste estudo estamos compreendendo que a Educação desenvolvida no Curso de Engenharia Civil, no particular da Universidade Federal do Rio Grande, constitui-se como um todo de relações sociais do processo de ensinar e aprender que precisa necessariamente estar impregnada de Educação Ambiental. Esse fato relaciona-se a outro que é o da necessidade de formar uma unidade entre Natureza e Homem, ambos mutuamente dependentes.

$O$ fato de a Engenharia Civil ser uma ciência que se materializa com mais evidência na transformação da Natureza, com fins imediatos de atender às necessidades primárias do homem para que ele tenha condições de viver para "fazer história", não pode ficar isolado de tudo que a mantém - a Natureza.

\footnotetext{
${ }^{4}$ Vocábulo utilizado em uma solenidade de formatura em pronunciamento do Prof. José Filgueiras, do Curso de Engenharia Química da FURG, com o significado de exercer a profissão de Engenheiro, exercer a atividade relacionada à Engenharia.
}

Revbea, São Paulo, V.16, № 5: 288-308, 2021.

revista brasileira educação ambiental 
Para fazer história os homens precisam antes de tudo satisfazer suas necessidades vitais, tais como: beber, comer, morar e vestir-se (MARX; ENGELS, 2002). A essas necessidades criamos fatos históricos que são produção dos meios que nos permitem satisfazê-las.

$\mathrm{Na}$ especificidade desse estudo, o anseio de "morar" torna-se a centralidade do que produz a Engenharia Civil, sem reduzi-la a esta parte de sua totalidade, mas a isolando, na particularidade de um estudo de caso, que visa à qualidade da habitação para além do proteger-se das intempéries ou de outros perigos, mas no sentido de criar condições de saúde e conforto no cuidado e proteção ao ser humano.

O mundo que circunda o homem apresenta um quadro onde há fenômenos extraordinários variados. As observações mais simples demonstram que esses fenômenos possuem ligações determinadas mais ou menos estáveis entre si, revelando no mundo determinada constância e certa regularidade.

Para o desenvolvimento desse estudo, situamos nosso problema de pesquisa no Ensino da Engenharia na qualidade de Formação do Engenheiro Civil como profissional que precisa ser também um Educador Ambiental. Nosso fenômeno de pesquisa tratou do processo educativo/formativo no Curso de Engenharia Civil da Universidade Federal do Rio Grande, de modo que o cuidado com a Natureza, o Homem e o Meio Ambiente tornem-se a centralidade no todo de seu currículo.

A prática social, no cotidiano do ser Engenheiro Civil, exige desse profissional uma formação com conhecimentos aprofundados e com especificidades no sentido da sustentabilidade, tanto no que diz respeito ao desenvolvimento creditado à construção civil e os serviços dela derivados, quanto à proteção do meio ambiente, principalmente no que tange à reciclagem de materiais, proteção, reabilitação, revitalização e restauração das construções. A atuação profissional do Engenheiro Civil, pelas práticas que efetua, está impregnada de Educação Ambiental.

A importância e a necessidade de uma reflexão crítica sobre a identidade do Engenheiro Civil com seus "quefazeres" pensamos ser o primeiro passo àqueles envolvidos na formação do futuro profissional dessa área, não apenas como alguém qualificado a desempenhar uma função produtiva de professor de Engenharia, mas que tenha o domínio sobre as exigências do mercado de trabalho.

Assim, esse engenheiro professor constitui-se como ser humanizador de múltiplas facetas, em que é capaz de compreender, aceitar, defender e melhorar a percepção da realidade de seus educandos. Certamente são características como essas que os assemelham a Educadores Ambientais, pelos ensinamentos e práticas que precisam desenvolver como saberes pertinentes à "Educação Ambiental", mesmo que tais saberes tenham sido ausentes em sua formação acadêmica inicial. 
Nessa compreensão, trabalhamos com a hipótese de que o Engenheiro Civil, com uma sólida formação em Educação Ambiental, enriquece sua humanidade e produz com naturalidade as condições de uma emancipação enquanto sujeito do processo de "ser mais", ao mesmo tempo em que se envolve politicamente com a formação crítica do Engenheiro Civil.

A Educação Ambiental, em suas múltiplas determinações, contempla em sua totalidade o Meio Ambiente como área de conhecimento técnico e pedagógico que contribui efetivamente na formação e no desenvolvimento da consciência crítica no cidadão, motivando a sua participação na gestão social e na sustentabilidade socioambiental.

A sustentabilidade socioambiental como processo de transversalidade da Educação Ambiental utiliza, entre outras estratégias, a mobilização social, a comunicação educativa-informativa e a formação permanente das pessoas. Porém, o modelo excludente do Capital faz com que o Estado, com suas leis, acabe negando sua função social de proteção coletiva ao meio ambiente, não negando seu caráter de classe.

As políticas públicas de meio ambiente e socioambientais mostram os limites incontornáveis que as tentativas de projetos como também de conhecimento têm nas mãos do sistema capitalista de produção.

A crítica feita pelo Materialismo Histórico Dialético de Marx levou-nos a entender a dificuldade de haver passos substanciais sob a lógica do capital para a resolução popular de problemas sociais, onde o que manda é a maximização de lucros, a concorrência e a propriedade privada. Na Engenharia Civil as formas de produção capitalista são incompatíveis com uma utilização racional de recursos.

Corroboramos nossa concepção de Educação Ambiental com a de Trein (2008) ao afirmar que a Educação Ambiental, apoiada em uma teoria crítica que exponha com vigor as contradições que estão na raiz do Modo de Produção Capitalista, deve incentivar a participação social na forma de uma ação política. Como tal, ela deve ser aberta ao diálogo e ao embate, visando à explicitação das contradições teórico-práticas subjacentes a projetos societários que estão permanentemente em disputa.

\section{A formação do engenheiro}

De acordo com Cocian (2009, p. 11), "a engenharia é arte da aplicação dos princípios matemáticos, da experiência, do julgamento e do senso comum, para implementar ideias e ações em benefício da humanidade e da natureza".

Conforme a Enciclopédia Miradora (1987), a Engenharia, antes de se constituir propriamente em um "quefazer" científico-tecnológico, exerceu, desde os primórdios da expressão humana, uma espécie de mediação entre a natureza e o homem. Da energia do fogo à energia do átomo, em seu constante relacionamento com a natureza, o homem foi aprendendo a desfrutá-la, a 
modificá-la e a adaptá-la, segundo suas necessidades. Pelos estudos que temos feito, podemos afirmar, com alguma fidelidade, que as atividades e as práticas sociais percursoras da Engenharia referenciam-se a muitas das primeiras modalidades de existência urbana.

Toda a natureza que nos é acessível constitui um sistema, um conjunto de fenômenos materiais concretos sensíveis. E, é necessário que admitamos, principalmente quando o foco dado é o materialismo dialético, que todos esses fenômenos se apresentam na realidade objetiva como matéria organizada, desde a estrela ao átomo e até mesmo a partícula de éter, desde que, assim, admitamos sua existência. Dessa forma, encontramos na Engenharia, pela sugestão de Cocian (2009), a arte da aplicação dos princípios matemáticos, da experiência, do julgamento e do senso comum, que somente o homem é capaz de fazer, de programar ideias e ações em benefício da humanidade e da natureza, imprimindo-lhe as modificações que julga necessárias.

Tanto a Engenharia enquanto profissão quanto o seu ensino no nível de escolas superiores coincidiram com a Revolução Industrial no século XVIII. Embora a Inglaterra tenha iniciado a Revolução Industrial antes da França, coube à França iniciar os primeiros cursos de Engenharia, um dos quais foi na Escola Politécnica de Paris, frequentada por Comte, entre 1814 e 1817. De acordo com Comte, a Escola Politécnica foi a primeira comunidade verdadeiramente científica, devendo servir de modelo para toda a Educação Superior.

Estudar um pouco dessa história, bem como entender como o ensino da Engenharia foi implantado e se desenvolveu no Brasil, remete-nos a provocar os objetivos da Revolução Industrial na Inglaterra e França e muito tardiamente no Brasil, com os fins sociais de uma formação humanista de engenheiros e sua relação com a natureza que lhe serve de matéria-prima.

Ser engenheiro em 1902, ou em qualquer momento entre 1850 e 1950, era ser participante em uma grande aventura, um líder em uma grande cruzada. A tecnologia, como todos poderiam sentir, estava fazendo avanços miraculosos e, como uma consequência natural, as perspectivas para a humanidade tornaram-se potencialmente brilhantes (FLORMAN, 1996).

De acordo com Florman (1996), foi um tempo em que o engenheiro estava presente no imaginário popular, não só na forma de personagem literário, cujas características eram identificadas com o idealismo e a construção do futuro, mas como seu protagonista.

No transcorrer dessa verdadeira "Idade do Ouro da Engenharia", expressão usada pelo autor supracitado, os engenheiros passaram a agregar um novo sentimento à sua autodefinição: seriam responsáveis pelas soluções dos problemas sociais e econômicos. Seriam eles os racionalizadores dos processos produtivos, os aproximadores da grande fraternidade humana, através das soluções práticas das estradas, pontes e canais. 
Neste tempo, diz ainda Florman (1996), todos pareciam acreditar que problemas de toda sorte seriam resolvidos com verdades científicas e suas aplicações tecnológicas. Essa conjuntura foi aos poucos sendo alterada, na cultura social e na cultura da profissão.

Nos anos 60, 70 e 80 do século passado, uma possível crise de identidade e de autoestima entre os engenheiros estava instalada e foi agravada pelo aparecimento dos movimentos ambientalistas, denunciando 0 envenenamento da comida, do ar e da água pelo desenvolvimento e uso de tecnologias, levando a acreditarem que esses problemas eram causados pelos engenheiros.

Ao fazer uma análise à distância, podemos observar que o contexto do qual fizeram parte os engenheiros e a sociedade daquele momento, em especial nos países europeus e nos Estados Unidos, nutriram a consolidação da Revolução Industrial, com todas as suas possíveis contradições e antagonismos.

Os efeitos da Revolução Industrial têm projetado, desde os seus primórdios até a atualidade, a moldura de um quadro caricaturizado, supostamente congelado no tempo, estereotipando a pessoa do engenheiro e cientificista como seres "frios e calculistas, pouco humanos e nada sensíveis. Os adjetivos que costumam definir ainda hoje o lado negativo de tal estereótipo são expressos pelo ditado popular "isto saiu da 'cabeça de engenheiro"'. Durante muito tempo os engenheiros foram considerados pessoas que se preocupavam somente com números, cálculos, construções, máquinas e engenhos, sendo esquecido que também são seres humanos.

De personagens que representavam heróis, esses profissionais da transformação da Natureza em meio ambiente em busca de conforto, passaram ao imaginário como aprisionadores da natureza humana em um universo transformado em máquina, fadado ao holocausto ambiental. $\mathrm{O}$ exemplo mais poético dessa crítica talvez possa ser identificado no filme "Tempos Modernos" (1936), de Charles Chaplin, autor da frase: "Não sois máquinas, homens é o que sois".

Possivelmente essas considerações de natureza histórica da profissão de engenheiro também façam parte da formulação relacionada ao ensino de Engenharia no Brasil, cujas origens militares são relacionadas à filosofia positivista, moldada pela lógica da verdade científica.

\section{A Engenharia Civil e o desenvolvimento sustentável}

A engenharia é conhecida como a profissão invisível ou discreta, devido a que a maioria das pessoas não tem ideia sobre o que os engenheiros fazem. Os cientistas descobrem o mundo que existe; os engenheiros criam o mundo que nunca existiu. (COCIAN, 2009, p. 43). 
A epígrafe acima leva-nos a pensar sobre a prática do engenheirar e ao entendimento da teoria como resposta às exigências da vida social, da luta de classes e, por sua vez, exercer influência sobre o processo social. Assim, a Engenharia como profissão só se materializa na criação do mundo que nunca existiu. Como sabemos, a consciência do homem não só reflete o mundo objetivo como também o cria.

Relacionar as práticas de engenheirar, no sentido de tornar visível a Engenharia como uma profissão discretamente invisível, precisa estar ligada ao que temos entendido como desenvolvimento sustentável.

Segundo Cocian (2009), a Engenharia com o conhecimento anunciado da existência do mundo cria o mundo que nunca existiu. Porém, criar um mundo que nunca existiu requer desenvolver essa criação no sentido da satisfação das necessidades humanas. Aqui, encontramos uma questão controvertida nas discussões possíveis sobre esse desenvolvimento para satisfação de necessidades humanas, e o sustentável da sustentabilidade como o evitar o esgotamento da natureza quando da criação do mundo que não existe.

A Engenharia, na totalidade de suas diferentes especificidades, particularizando a Engenharia Civil e seus conhecimentos, como conteúdo formal de uma nova sociedade de convívio, precisa estar ciente que uma outra Engenharia tem de se acostumar a pagar muito caro para a natureza o que dela for extraído em excesso porque, por sua vez, essa mesma natureza vai cobrar caríssimo o que nela depositamos.

Atualmente parece difícil abordar a questão da durabilidade das construções sem mencionar a sua posição frente ao desenvolvimento sustentável porque, certamente, a durabilidade é um dos fatores mais importantes neste enfoque. É errôneo realizar a demolição de uma construção em concreto num curto período de tempo sem solução para os resíduos dela demandados.

Assim, o ensino da Engenharia Civil precisa anunciar em seu currículo a presença da Educação Ambiental como necessidade pedagógica, e como forma de estabelecer relações adequadas para o convívio humano com a natureza em sua totalidade.

Entendemos o engenheiro inserido como elemento do ciclo social, cultural e produtivo, juntamente como os demais seres humanos, como principal recurso para a sustentabilidade da própria "justiça social".

A relação da Engenharia com o desenvolvimento sustentável perpassa pela aridez de um mundo de números, o que vem somente interessar a essa relação em um mundo de homens, de seres humanos.

$\mathrm{Na}$ relação entre Engenharia e Desenvolvimento Sustentável não interessa a economia entendida como fechamento de contas, equilíbrio monetário ou fiscal, mas um mundo-relações em lugar de um mundo-objetos. Um mundo onde possamos interpretar com os "engenheiros", no especial deste 
estudo, a realidade sempre em movimento, em transformação. Tencionando que as relações entre os homens, entre os homens e o suporte físico e natural, entre outras, sejam menos importantes que as coisas.

O mundo atual, apesar do reconhecimento da importância do conceito de desenvolvimento sustentável, que levou à Conferência Rio-92, caminha concretamente por ramos que desafiam qualquer noção de sustentabilidade. Desenvolvimento sustentável é um conceito que pensamos ser indispensável nas discussões sobre política do desenvolvimento, incluindo nela a formação de engenheiros civis.

O Engenheiro Civil moderno tem efetivamente de ocupar-se com os problemas sociais, com os valores inerentes à sociedade em termos de igualdade e solidariedade, requerendo para tal uma abordagem holística. Tal abordagem, que de ser apreendida e sentida no ensino superior e nos programas de formação profissional, deve insistir que atualmente o modo de encontrar solução para a superação de um problema não se resume meramente à opinião de um só especialista, mas que é necessário, perante os conflitos reais que existem na sociedade, um trabalho de equipe, de discussão, consenso e aproximação sucessiva.

Nesta perspectiva, o Engenheiro Civil moderno terá então de se ocupar com o funcional, o social e o estético, terá de encontrar soluções que sejam aceitáveis do ponto de vista político, econômico, social e ecológico. Para tal, além dos conhecimentos científicos e tecnológicos, necessita ter seus sentidos desenvolvidos para que suas práticas prosperem no sentido do bem-estar social do Homem e da Natureza.

É nesse sentido que pensamos que o engenheiro pode vir a desempenhar um papel fundamental numa transição rumo a uma sociedade que tenha como meta a satisfação das necessidades humanas, produtora de valores de uso.

Esses atributos na formação do engenheiro, em especial o civil, na organização desse estudo, não poderão ser eximidos ou mesmo afastados da ligação com a categoria do Desenvolvimento Sustentável, tendo em vista que a totalidade desse fenômeno não fica fora da Natureza no seu todo. Desenvolvimento sustentável na relação com a Engenharia Civil não pode ser divorciada do conceito de "ecodesenvolvimento", por tudo que isso significa.

O Engenheiro Civil, praticando o ato de engenheirar, não pode ser alheio ou indiferente às questões ecológicas e ambientais na materialização de seu trabalho. Necessita estar inserido profundamente e ser participante do progresso da sociedade. Precisa trazer consigo, em sua compreensão, o conceito de "Ecodesenvolvimento" como uma nova concepção alternativa de política do desenvolvimento, onde na relação direta da Natureza com o Homem e vice-versa está a razão de seu produto enquanto trabalho social.

No trabalho do Engenheiro Civil, cuja matéria-prima está no potencial da natureza, é possível modificar algumas tendências equivocadas de crescimento,

revista brasileira educação ambiental 
que levam à degradação tanto da natureza como do trabalhador, assim como pelo campo da Educação Ambiental, ainda fragilmente trabalhado nos currículos dos cursos de Engenharia Civil.

Frente ao exposto, podemos comprometer o Ensino da Engenharia para que na formação preconizada em seu Projeto Político Pedagógico trabalhe saberes ambientais de modo a criar condições de manutenção de estabilidade ecológica e econômica até um futuro remoto. Sabemos que no todo da educação, o estado de equilíbrio global poderá ser planejado de tal modo que as necessidades materiais básicas de cada pessoa no Planeta sejam atendidas, e que cada pessoa tenha igual oportunidade de realizar seu potencial humano individual.

O autor Ignacy Sachs (2002), economista polonês, naturalizado francês, revela que se deve ter uma visão holística dos problemas da sociedade, não focando apenas na gestão dos recursos naturais. Alinhamos nosso entendimento a ele, mas resgatamos a categoria de totalidade do Materialismo Dialético para aprofundar nosso pensamento, visando o conhecimento das contradições que efetivam o movimento que determina e constitui a realidade, tanto a objetiva quanto a subjetiva.

Nesse processo, recorremos novamente a Sachs (2002), para auxiliarnos na condução de desmistificar, na Engenharia, alguns princípios que pensamos ser interessantes sobre o Ensino da Engenharia, no intuito de incorporar em seus objetivos muito além dos conhecimentos técnicos que apresenta como materialidade de obras.

Este pensador polonês integrou basicamente seis princípios básicos, onde apoia a nova visão do desenvolvimento sustentável como "ecodesenvolvimento", que precisam guiar os caminhos do desenvolvimento. Em nossos estudos transpusemos três desses princípios para a formação teórica e para a ação prática do Engenheiro Civil, que busca sustentabilidade ambiental.

Desta forma, trazemos para o diálogo, no que diz respeito à formação do engenheiro, os saberes que levam esse profissional a proporcionar, no produto de seu trabalho, a "satisfação das necessidades humanas", ponto principal da concepção teórica que trabalhamos aqui:

"A solidariedade com as gerações futuras", como forma de não extrair da natureza mais do que ela suporte, não dificultando ou mesmo impedindo sua regeneração. Deixar um ambiente favorável para se viver com saúde e prosperidade.

Isto levanta a iminência de pensarmos no sentido amplo da "participação da população envolvida" no processo. Aqui há, além do cuidado das satisfações das necessidades humanas, na formação do Engenheiro Civil, que se ter claro e presente quais necessidades a população apresenta e precisam ser atendidas, além de se buscar a participação da sociedade para a solução de problemas coletivos e sociais, amparando nas demais ciências para melhor fazer a leitura do mundo. 
Se o ambiente encerra nele uma compreensão de totalidade de nossa condição humana na busca de harmonia com todos os fatores da realidade, o ensino de Engenharia vai precisar, na sua organização e funcionamento, pensar um currículo, dentro do que sua prática vai materializar, que crie condições de um desenvolvimento que possamos chamar de sustentável, fazendo o esforço de pôr todos os fatores que se apresentam na realidade em conjunto, de modo que "a preservação dos recursos naturais e do meio ambiente em geral" seja um caminho que afaste, na especificidade do fenômeno que estamos estudando - o Ensino da Engenharia Civil na perspectiva da Educação Ambiental - como forma de emancipar no "sujeito ecológico" - Engenheiro Civil - os sentidos humanos do conhecer e compreender em sua prática o que precisa ser transformado.

No modelo vivenciado em nossa sociedade temos encontrado um processo crescente do mercado e da mercantilização, à custa dos "pseudos" equilíbrios naturais das relações sociais e da autonomia individual, que tem de ser revista, antes de tudo, já nos cursos de Engenharia Civil, se o setor quiser pensar uma sociedade sustentável e, mais do que isso, se a preocupação da formação desse profissional não se limitar a uma simples questão de sobrevivência física, mas, sim, na busca constante de qualidade de vida.

Jung et al. (1992) já nos haviam alertado para os desafios que ainda teremos pela frente, no sentido de superar muitas de nossas limitações: "é ilusório imaginar que o homem possa dominar e controlar a natureza, se ele não foi ainda capaz de controlar e enxergar sua própria natureza" (JUNG et al., 1992, p. 28).

O desenvolvimento sustentável, que abrange muitas e diversas dimensões, precisa de nossa atenção para as diferentes bases materiais do sistema industrial capitalista de produção, que aponta para uma sustentabilidade inerente, onde se torna necessário apontar as limitações das análises que se têm mostrado sobre sustentabilidade, as quais procuram definir modelos abstratos de desenvolvimentos sustentáveis, quando desconsideram ou até mesmo ignoram a realidade histórica, a própria base de aplicação dos modelos apresentados como verdadeiros.

Temos pensado com afinco neste estudo em destacar como adequada a formação de engenheiros civis, o bom senso no preservar a qualidade do ambiente para a restauração, o planejamento e a manutenção dos habitats essenciais à espécie humana, assim como realizar uma gestão sustentável dos recursos dos reinos dos seres vivos, como a melhor forma de atingir o desenvolvimento necessário.

Todavia, a busca de modelos sustentáveis requer uma compreensão da totalidade dialética dos movimentos da natureza e da sociedade, capaz de integrar as condições materiais adequadas da sustentabilidade (equilíbrios físicos - químicos - biológicos) à compreensão do funcionamento histórico da sociedade humana. 
Isto nos remete novamente à ideia trazida sobre o "ecodesenvolvimento", sinônimo de um processo de sustentabilidade referenciada na qualidade de vida, na elaboração de um sistema social garantindo emprego, segurança e respeito a outras culturas e em um programa de educação coerente e consistente, firmado na produção de saberes e práticas voltadas à "Felicidade" dos seres humanos. Programa esse que consiga garantir uma igualdade social pela satisfação das necessidades essenciais das comunidades humanas atuais e futuras, assim como melhorar a qualidade de vida notadamente, pelo trabalho social do Engenheiro Civil, no favorecimento ao acesso de todos a uma moradia de qualidade, à medida que possa aumentar a eficácia econômica, ao favorecer a realização de uma ótima gestão dos recursos humanos, naturais e financeiros, adequados à satisfação das comunidades.

\section{A construção civil na dimensão do desenvolvimento sustentável}

Temos participado de alguns eventos, dentre Congressos, Seminários e Simpósios, que nos apresentam as mais diversas liturgias sobre Desenvolvimento e sustentabilidade, Crises ambientais e problemas ecológicos, entre as mais diferentes perspectivas teóricas de se ler o mundo e a própria palavra, como rememora Freire $(1987 ; 1996)$ em seus escritos políticos pedagógicos.

Nesses encontros realizamos algumas anotações sobre pensamentos de palestrantes, sem trazer a identificação de quem os expôs, que nos chamaram a atenção pela forma como foram expressos. Temos anotado que "a atual crise ecológica é apenas o reflexo dessa contradição, do caráter

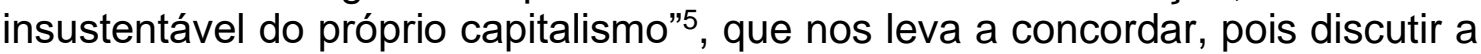
questão ecológica e ambiental sem discutir os fundamentos materiais, institucionais, políticos, econômicos e culturais da nossa sociedade, resulta em um discurso vazio, sem consistência teórico-prática.

Outro aspecto a considerar e dar destaque diz respeito a um trabalho apresentado em outro desses eventos, em que foi enfatizado que "a sobrevivência não é tanto porque a terra vai desaparecer. A terra vai sobreviver a todos esses desastres ecológicos, o que pode acontecer é que desapareça uma espécie, dentre outras, a qual estamos profundamente ligados - o ser humano"6.

Nosso interesse pelo Materialismo Dialético de Marx, ao mesmo tempo em que nos fez anotar, também nos faz desconfiar se existiria alguma coisa com a ausência do ser humano. Essa é uma boa discussão, se colocarmos a Crise Estrutural do Capital como um dos eixos da discussão junto com o modo de Produção Capitalista e a sua essência, a "Propriedade Privada".

${ }^{5}$ Anotação realizada em uma palestra de evento nacional. [s.n.t.].
${ }^{6}$ Idem.

Revbea, São Paulo, V.16, № 5: 288-308, 2021. 
Outras anotações poderiam enriquecer o presente capítulo com bons diálogos. Todavia queremos trazer aqui, dentro da compreensão do Materialismo Histórico e Dialético, a questão do "Desenvolvimento" como processo de movimento resultante da Luta e Unidade dos Contrários (MAO-TSE-TUNG, 2009) promovida pelo processo de superação e resolução de contradições.

Cabe trazer à nossa fundamentação três dimensões que no campo da Educação Ambiental se têm teoricamente trabalhado, ou mesmo somente discutido, dispostas como Sustentabilidade e o desenvolvimento que ela produz, ou vice-versa. Que desenvolvimento sustentável é esse que se busca?

Ao anunciado como categoria filosófica do Materialismo Dialético da Contradição acrescentamos algumas dimensões do Desenvolvimento Sustentável consideradas, na realidade, como saberes que se tornam ambientais. No entanto, tais saberes ambientais são necessários à formação da consciência crítica, no geral, e na dos egressos dos Cursos de Engenharia Civil no particular que, em nosso entendimento, precisam fazer parte do senso comum do engenheiro civil como saberes educativos provindos da Educação Ambiental quando transversalizados em todas os componentes curriculares desenvolvidos no Curso.

No ano de 1987 houve a divulgação do Relatório Brundtland, intitulado "Nosso futuro comum", pela Comissão Mundial sobre Meio Ambiente e Desenvolvimento das Nações Unidas que popularizou a expressão "desenvolvimento sustentável" e seu conceito que tem sido considerado o mais próximo do consenso oficial. Neste documento o desenvolvimento sustentável é concebido como: "O desenvolvimento que satisfaz as necessidades presentes, sem comprometer a capacidade das gerações futuras de suprir suas próprias necessidades".

Mesmo sendo um conceito que se popularizou sem uma crítica que possibilitasse avançar em uma compreensão politizada sobre o futuro do Planeta e da Humanidade, o Relatório Brundtland destaca três importantes componentes, que sentimos ser fundamentais para o desenvolvimento sustentável em sua totalidade: proteção ambiental, crescimento econômico e equidade social.

Esses três componentes nos possibilitam fazer uma analogia com as práticas da Engenharia Civil, principalmente no trato da proteção ambiental de modo a manter e aumentar a durabilidade dos habitats essenciais à espécie humana, qualificar o crescimento econômico, favorecendo a gestão dos recursos humanos, naturais e financeiros, aumentando a satisfação das comunidades e, por fim, ampliando as condições necessárias à equidade social com fins de melhor satisfazer as necessidades humanas atuais e futuras com o acesso a moradias de qualidade. 


\section{A primeira dimensão do Desenvolvimento Sustentável e o material concreto como Produto Sustentável}

Pensamos em trazer para reflexão a primeira dimensão desse desenvolvimento sustentável, passível de ser abordada com base na análise do ciclo de vida - $\mathrm{ACV}^{7}$ contidas no Relatório Brundtland. O termo ACV se refere ao cálculo do impacto ambiental de uma "unidade funcional" como, por exemplo: uma casa ou uma rodovia sobre o ambiente - desde a sua concepção até o seu desaparecimento completo.

A ACV é uma técnica desenvolvida para mensuração dos possíveis impactos ambientais causados como resultado da fabricação e utilização de determinado produto ou serviço.

Tal análise leva em consideração todos os materiais utilizados, a energia (sob forma térmica, elétrica ou de transporte) e as emissões gasosas ou aquosas. Esses impactos formam um conjunto de dados e podem ser expressos diferentemente segundo os objetivos buscados e os métodos utilizados.

A norma internacional ISO-14040 de qualificação da avaliação dos aspectos ambientais e os impactos potenciais ao longo da vida de um produto, desde a aquisição da matéria-prima, passando por produção, uso e disposição, ainda não se apresenta, aqui, muito clara.

Embora as categorias gerais de impactos ambientais que devam ser consideradas incluam o uso de recursos, a saúde humana e as consequências ecológicas, é por meio da norma francesa PO1-010, recentemente homologada, que se expressa a análise do ciclo de vida levando em consideração, além destes, outros vinte impactos ambientais, formando um conjunto de quatrocentas bases de dados medidas ou calculadas.

Em uma análise mais detalhada desta Norma, no que tange à Natureza, ao ser humano e ao meio ambiente, podemos dizer que a ACV ainda está em um estágio inicial de desenvolvimento de uma sustentabilidade desejada, pois algumas fases da técnica de ACV, em nosso entendimento, como a avaliação de impacto na natureza, os aspectos econômicos ou sociais de um produto ainda estão em relativa infância.

A produção propriamente do "concreto" em Engenharia Civil, considerado em si o material concreto como produto sustentável, é destacada no presente estudo dada a devida atenção ao conhecimento produzido pela prática da construção civil, com vistas a dar ênfase à necessidade de identificar e compreender a possível sustentabilidade nas relações do homem na e com a natureza, relacionando-as com a demanda do fundamento do trabalho de engenheirar.

${ }^{7}$ A ACV enfoca o ciclo de vida de um produto, desde a extração de matérias-primas, passando pelas etapas
de produção, distribuição e utilização, até sua destinação final. de 
O principal defeito do concreto é a utilização de recursos energéticos e não energias renováveis. Sua principal qualidade, entretanto, é a durabilidade, que fornece um ciclo de vida muito longo e limita, por conseguinte, sua utilização.

É preciso relativizar o impacto direto do concreto pela função que ele exerce e os ganhos dos impactos ulteriores que gera. Em uma construção que necessite de manutenção regular é importante poder inverter totalmente a análise do ciclo de vida de todo conjunto da obra.

As avaliações realizadas por meio de cálculos mostram que a fase de construção não representa mais que, aproximadamente, $10 \%$ do impacto ambiental de um edifício, ou de um quilômetro de uma rodovia. Essas proporções dão uma ideia do impacto da qualidade de uso das edificações e do impacto da durabilidade das obras.

É preciso lembrar que na França o aquecimento dos edifícios com combustíveis fósseis representa $18,4 \%$ das emissões totais, praticamente o mesmo que a agricultura $(19,3 \%)$ e a indústria (20\%). O aquecimento das edificações está com crescimento de $14 \%$ em relação a 1990 (ano de referência do Protocolo de Quioto de redução de gases do efeito estufa), quando a indústria estava em baixa de $22 \%$.

Isso salientamos por identificarmos nesses saberes não o conteúdo didático pedagógico do estudo da Engenharia Civil, mas por apontarem na formação desse engenheiro a necessidade de saberes técnicos se tornarem ambientais.

Desta forma, enfatizamos que esses saberes não são ideologicamente neutros nem alheios a interesses econômicos e sociais. A materialidade desses processos está na relação entre o real do concreto, o conhecimento de sua ciência e a realidade de seus efeitos.

As ciências não apreendem diretamente as coisas empíricas, mas estabelecem paradigmas que permitem dar conta das relações fundamentais entre os processos que constituem seus diferentes objetos de conhecimento.

Ademais, reconhecemos a importância de fazer uma relação didática do uso do conceito, aqui em dois entendimentos, um primeiro como efeito de conhecimento do real, que produz articulação com os demais conceitos que constituem uma teoria científica, e o segundo como efeito de sentido, com o real por meio do objeto de conhecimento de uma ciência.

Essa relação está nos significados de concreto enquanto material concebido como categoria da teoria materialista dialética, e o concreto como substantivo próprio, enquanto interação de causas que reúnem as condições favoráveis para a existência do fenômeno enquanto o material utilizado na construção civil, composto por uma mistura de água, cimento e agregados. $\mathrm{O}$ cimento é o aglomerante do concreto que une os agregados. Estes podem ser agregados miúdos (areias) ou agregados graúdos (pedras britadas). 
Esses conceitos dão conta na prática da produção do real na Engenharia Civil que, ao parafrasear Karl Marx (2008), destacamos "a concretude de pensamento, como síntese de múltiplas determinações". É o que queremos trazer para reflexão e crítica no entendimento de sustentabilidade que precisa orientar o desenvolvimento produzido pela Engenharia Civil, no seu processo de materialização do mundo.

Corroborando a presente discussão, Marx afirma:

O concreto é concreto porque é a síntese de múltiplas determinações [...] por isso, o concreto aparece no pensamento de síntese, como resultado e não como ponto de partida, embora seja o verdadeiro ponto de partida e, por conseguinte, também o ponto de partida da intuição e da representação (MARX, 2008, p. 258,259$)$.

A relação que pensamos trazer é que na Engenharia esse concreto também é a síntese de múltiplas determinações, no sentido de compreendermos que totalidade é essa, enquanto o concreto a que Marx se refere é síntese de múltiplas determinações, de múltiplos conceitos, apreendidos pela produção teórica dos conceitos que integram a síntese de múltiplas determinações (fenômenos) que constituem, ao mesmo tempo, o princípio do processo real.

Nessa linha de pensamento, Enrique Leff (2002), em sua Epistemologia Ambiental, nos ajuda a compreender a relação que buscamos fazer para que conceitos básicos no ensino da Engenharia Civil sejam apropriados criticamente, como um processo epistemológico. Esta epistemologia, de acordo com Leff (2002), não deve ser confundida com o pragmatismo epistêmico atribuído a Marx, no qual o conhecimento se reduziria ao saber das coisas enquanto objeto de trabalho.

Ao trazermos como fundamento teórico desse estudo a epistemologia materialista, estamos defendendo, como Leff (2002), que o conhecimento, seja qual for, e na especificidade de nosso fenômeno de pesquisa o ensino de Engenharia em curso superior, não pode ter nem trabalhar a concepção da produção teórica como sendo o simples reflexo do real no pensamento, pois em nosso entendimento seria o que o autor chama de "pragmatismo epistêmico".

\section{A segunda dimensão do desenvolvimento sustentável}

$\mathrm{Na}$ busca de fundamentação conceitual, dentro de uma perspectiva Materialista Dialética, trazemos para dialogar com o ensino da Engenharia Civil um processo de ensino-aprendizagem que emancipe os sentimentos que nos fazem ser humanos, a segunda dimensão do desenvolvimento sustentável, por entendermos que precisamos encontrar uma certa sustentabilidade para os efeitos da materialização do processo de engenheirar. 
A dimensão do desenvolvimento sustentável que estamos pensando, sem dúvida alguma, perpassa pela igualdade social, onde as oportunidades são para todos. Isto, em nosso referencial de realidade, está diretamente direcionado à construção e à habitação, a moradia.

Quando falamos de igualdade social estamos falando em assumir que todos os fatores da realidade, por estarem em profunda correlação, precisam estar a serviço de todos, independentemente das causas que possam nos diferenciar. Correlação essa que pode gerar um "mau" ou "bom" ambiente de vida. $\mathrm{E}$, em nosso entendimento, é nela que se encontra o destino de nossa realidade cotidiana, como também o destino de nossa sociedade.

A perspectiva de que todos precisam usufruir de tudo denota com clareza nossa postura política dentro da academia. Isso no trato social da construção civil pode estar relacionado ao papel dos materiais de construção usados na construção de moradias sociais, quando essas, na habitação popular, como no Programa "Minha Casa, Minha Vida", tornaram-se um verdadeiro jogo político. Certamente é preciso não só construir com rapidez, menor custo e qualidade, para satisfazer necessidades humanas prementes e das gerações futuras.

A comparação de diferentes materiais de construção deve ser feita sob o ponto de vista da análise do ciclo de vida desses materiais. O concreto está, evidentemente, no centro dessas questões na medida em que ele representa $90 \%$ do mercado da construção.

Se a problemática pode ser colocada em termos simples, ela se torna difícil em sua abordagem completa. A relação entre o investimento necessário e o custo posterior de funcionamento das obras faz parte de equações difíceis de serem resolvidas.

A equidade social ainda não foi alcançada em nenhuma parte do mundo, devido ao Modo de Produção Capitalista predominante. Isso significa que estamos há séculos da igualdade social sonhada pelos que são "realmente humanos". Queremos dizer, na cidade ou no campo, embora todos tenham o direito - como processo de igualdade - de votar no governante, nem todos têm o mesmo direito - a mesma igualdade - de habitar um local saudável.

Nesse contexto, o concreto da Engenharia Civil pode contribuir para a solução materialista dialética do concreto desse problema sendo, de longe, o material, enquanto "síntese de múltiplas determinações", mais econômico e utilizado no mundo da construção.

Referir-nos aqui apenas a moradias nesta dimensão social seria limitante, uma vez que o ordenamento urbano hoje tão apreciado, com as zonas de pedestres e de transportes coletivos, tem sido o maior consumidor de concreto.

Não podemos fugir, também, do sentido estético, onde a Engenharia Civil precisaria andar de mãos dadas com o ensino da Arquitetura. A construção 
civil contribuiria, assim, para a sustentabilidade do desenvolvimento, quando pode pensar em não só melhorar o relacionamento dos homens com a natureza, mas mudar nosso estilo de desenvolvimento com vistas a um ambiente melhor, para conviver melhor nele.

A diversidade de aspectos dos concretos é tão grande, com o uso colorido, texturizado, matizado, que poucas pessoas - por falta de igualdade conseguem esse material camaleão que se funde harmoniosamente na paisagem urbana. Se no ambiente está uma compreensão global de assumir nossa condição humana - na busca de uma outra harmonia com todos os fatores da realidade objetiva, certamente, o desenvolvimento sustentável, diremos novamente, seria o esforço de pôr todos esses fatores em conjunto.

\section{A terceira dimensão do Desenvolvimento Sustentável}

O autor Ramón Folch (1978), doutor em Biologia pela Universidade de Barcelona, em seu livro "Sobre Ecologismo y Ecologia Aplicada", afirma que não há problemas ecológicos ou ambientais. Assim, também enfatiza que a solução não está em fazer cursos de Ecologia, que embora sejam muito importantes, não são mais que os cursos de Ciências Políticas, de Artes ou Engenharia.

Compreendemos, por meio de seu pensamento, que o ambiente é tão importante que não podemos deixá-lo sob a responsabilidade somente dos ecólogos, tal qual a cidade, como algo importante, não se pode deixar sozinha sob a responsabilidade dos arquitetos.

Continuando no âmago do pensar do autor, ele ratifica, pela seguinte afirmação: "Não há problemas ecológicos ou ambientais, os ecossistemas funcionam" (FOLCH, 1978). Logo, em sua concepção, o que há são problemas de inserção incorreta do homem e suas atividades nos sistemas ecológicos, que para o autor são coisas distintas, completamente diferentes.

Enquanto em nossa tese doutoral fomos buscar compreender como o Ensino de Engenharia Civil, ao adotar em seu currículo a Educação Ambiental, poderá melhor criar possibilidades de emancipação humana, tivemos a compreensão, como Folch (1978) nos alerta, de que a Engenharia Civil sozinha não salvará a realidade. Ela poderá, sim, ajudar na organização e na sistematização de uma outra e nova cultura do homem, o que Rubén Pesci (2004) chama de "novo humanismo", que seja capaz de interagir adequadamente com os sistemas naturais.

É no todo desse sentimento que destacamos como terceira dimensão o Desenvolvimento Sustentável como compreensão necessária para o Ensino da Engenharia Civil. Em nosso entendimento, toda e qualquer crise, ou problemas que possamos estar enfrentando ou mesmo ainda enfrentaremos, tem sua origem no Modo de Produção Capitalista reinante em nossa sociedade, como forma de produzir nossa existência. 
Assim, destacamos nessa terceira dimensão a questão econômica, que de alguma forma desnuda as crises ambientais e ecológicas existentes. Da abordagem marxista poderiam ser incorporadas suas análises críticas, bem como toda a concepção dialética da história, possibilitando a construção de perspectivas e cenários alternativos.

Essas análises, em conjunto com novas compreensões científicas do mundo e da realidade, poderão levar a formulações de novas perspectivas analíticas que melhor descrevem a atual fase de transição histórico-filosófica pela qual passa a humanidade nessa segunda década do século $X X I$, onde o Ensino Superior, a formação do Engenheiro Civil e a Educação Ambiental precisam figurar como processos transformadores da Economia Política.

Assim, a eficiência econômica nos aparece como a terceira dimensão, a ser considerada no Ensino de Engenharia Civil. Provavelmente é a que se aproxima mais diretamente da noção de durabilidade dos materiais que são matéria-prima para a construção civil, e a qualidade do produto do trabalho da Engenharia Civil.

Referindo-nos ao exemplo do "concreto" como síntese de múltiplas determinações, organizados com materiais duráveis, no processo da eficiência econômica, o concreto não necessita, na maioria dos casos, de nenhuma proteção, nem manutenção específica, que acarretaria despesas.

A grande maioria das estruturas de Engenharia Civil é em concreto aparente que demanda apenas uma inspeção visual periódica. No processo da economia, como forma de equalizar custo-benefício, há obras com problemas que são praticamente sempre aquelas que apresentam defeitos de concepção ou de execução o que, em nosso entendimento, pode se dar por diversos fatores, dentre eles: quando derivado de falha técnica, poder econômico, com barateamento na qualidade do material ou na qualidade da força de trabalho. Ambos ligados de alguma forma à sustentabilidade dada pelo desenvolvimento da formação em sua totalidade.

$\mathrm{Na}$ maioria dos casos, a otimização econômica está em evitar as proteções, que consomem tempo e recursos, aceitando-se o risco de problemas específicos de durabilidade. Todavia, o concreto, com as qualidades que reúne, pode ser pintado, revestido, possuir algum tratamento específico ou conter armaduras inoxidáveis, entre outros aspectos, visando reduzir totalmente o risco de degradação.

Esses saberes, por mais simples que possam parecer, encerram em si conhecimentos que expressam sinais de transversalidade de saberes ambientais que, quando trabalhados didática e pedagogicamente no exercício do Ensino da Engenharia Civil, efetivam um processo educativo que estamos chamando de Educação Ambiental.

O ambiente estabelece potenciais e limites às formas e ritmos de exploração de recursos, condicionando os processos de valorização, acumulação e reprodução do capital, quando saberes, que estamos julgando

revista brasileira educação ambiental 
ambientais, protegem o concreto, não como forma estética, mas na forma de economia de gastos futuros, na sua conservação.

$\mathrm{Na}$ Engenharia Civil, em particular, a Educação Ambiental tem se apresentado como saberes dentro da racionalidade econômica, científica e tecnológica de nossa modernidade, ao mesmo tempo em que, pelo histórico da função social da Engenharia, a Educação Ambiental, com seus saberes próprios, não tem conseguido ser aproveitada ou mesmo reinventada para servir necessidades humanas, tanto as políticas como as econômicas.

\section{Considerações finais}

Entendemos que a Engenharia, quando politizada para a formação de profissionais humanistas, vai requerer para suas práticas conhecimentos que levem à construção de uma racionalidade ambiental independentemente da perspectiva ideológica e política na qual se gera sua demanda.

A construção de uma racionalidade ambiental, no Ensino da Engenharia, exige transformações dos paradigmas científicos tradicionais que ainda imperam nas escolas de Engenharia de todo o Brasil. Entretanto, exigirá outros conhecimentos com organização interdisciplinar que deem conta da necessidade de compreender a complexidade dos múltiplos processos que têm conduzido a humanidade a práticas nada sustentáveis.

A relação que temos estabelecido em nossas práticas docentes, como professores de Cursos de Engenharia Civil, Arquitetura e Educação Ambiental, enquanto formadores de recursos humanos, precisa transcender a criação de um espaço acadêmico, simplesmente formado pelo conjunto de disciplinas tradicionais, com metodologias homogêneas totalizantes das ciências das Engenharias, consideradas de valor universal.

Tratar, por exemplo, o cálculo como disciplina que visa na estrutura da obra a segurança e o econômico do material a ser usado é interessante, mas na maioria das vezes é reservado a casos muito particulares, como o das pontes de grande porte ou do armazenamento de rejeitos nucleares. Todavia, precisa essa disciplina tomar outros significados - como o que poderia ser dado pelas "Ciências Ambientais" (LEFF, 2002) enquanto saberes ambientais.

Por sua vez, sentir a necessidade da incorporação de saberes ambientais nas práticas científicas da Engenharia e nas práticas docentes desenvolvidas no Ensino de Engenharia Civil, vai além de um requerimento de atualização dos currículos universitários.

No Ensino de Engenharia, como em todo e qualquer outro curso de formação profissional, o saber ambiental não emerge de uma reorganização sistêmica dos conhecimentos atuais. Temos compreendido com Leff (2002) que estes saberes se gestam, se organizam e sistematizam por meio de transformações de um conjunto de modelos de conhecimento incluindo, aí, as formações ideológicas, fundados sempre em um Fenômeno Material Social 
Concreto Sensível, que nos questiona e cujas contradições ao se resolverem os ultrapassam, criando outras contradições, novos conhecimentos.

Assim, podemos pensar no uso dos conceitos de desenvolvimento sustentável, construído em complexidades evidentes, contrárias às tentativas permanentes de simplificação de problemas.

A sustentabilidade do desenvolvimento demanda a produção de um corpo complexo e integrado de conhecimentos, não só sobre o trabalho em si da Engenharia Civil, porém sobre os processos naturais e sociais que intervêm em sua gênese e em sua materialização.

Os saberes ambientais, no rol dos saberes necessários para um ensino interdisciplinar no Curso de Engenharia Civil, assumem, em nossa compreensão, dimensões a serem consideradas nas análises que possamos vir a fazer da realidade objetiva que nos é apresentada, uma possível e adequada intervenção na natureza e na sociedade como um todo.

\section{Referências}

COCIAN, L. F. E. Descobrindo a Engenharia: a profissão. Canoas: Gráfica Ulbra, 2009.

CARVALHO, I. C. M. Educação Ambiental: a formação do sujeito ecológico. 2ed. São Paulo: Cortez, 2006.

COMISSÃO MUNDIAL SOBRE MEIO AMBIENTE E DESENVOLVIMENTO. Relatório Brundtland. Oxford, KU: Oxford University Press, 1987.

FLORMAN, S. The existential pleasures of engineering. New York: St. Martin's Griffin, 1996.

FOLCH, R. Ambiente e desenvolvimento sustentável: estratégias a partir de Porto Alegre. Porto Alegre: Editora da URGS, 2004.

FOLCH, R. Sobre Ecologismo y Ecologia Aplicada. Barcelona: Ketres Editora, 1978.

FREIRE, P. Pedagogia do Oprimido. 17ed. Rio de Janeiro: Paz e Terra, 1987. FREIRE, P. Pedagogia da Autonomia: Saberes Necessários à Prática Educativa. Rio de Janeiro: Paz e Terra, 1996.

JUNG, C. G. et al. O homem e seus símbolos. Rio de Janeiro: Nova Fronteira, 1992.

KRAPÍVINE, V. Que é materialismo dialético? ABC dos conhecimentos sociais e políticos. Moscovo: Edições Progresso, 1986.

LEFF, E. Epistemologia ambiental. São Paulo: Cortez, 2002.

LOUREIRO, C. F. B. Trajetórias e fundamentos da Educação Ambiental. 4ed. São Paulo: Cortez, 2012. 
MARTINI, R.M.F. Antecipação de Kant ao problema das vertentes epistemológica e ética da educação. Educação \& Realidade. Porto Alegre, v. 18, n. 2, p. 109-118, jul./dez. 1993.

MAO TSE-TUNG. Sobre a prática \& sobre a contradição. São Paulo: Expressão Popular, 2009.

MARX, K. Contribuição à crítica da economia política. 2ed. São Paulo: Expressão Popular, 2008.

MARX, K; ENGELS, F. Ideologia Alemã. São Paulo: Martins Fontes, 2002.

PESCI, R. Um novo humanismo e o planejamento ambiental. In: MENEGAT, R.; ALMEIDA, G.; SATTERTHWAITE, D. Desenvolvimento sustentável e gestão ambiental nas cidades: estratégias a partir de Porto Alegre. Porto Alegre: Editora da URGS, 2004. p.81-128.

SACHS, I. Caminhos para o desenvolvimento sustentável. Rio de Janeiro: Garamond, 2002.

TOZONI-REIS, M.F. Formação de educadores ambientais e paradigmas em transição. Ciência \& Educação, v. 8, n. 1, p. 83-96, 2002.

TREIN, E. Conceitos de Educação Ambiental. Ministério do Meio Ambiente: Salto para o Futuro, 2008. Disponível em: <https://www.mma.gov.br/educacaoambiental/politica-nacional-de-educacao-ambiental.html>. Acesso em: 23 jul. 2014. 